\title{
Congenital heart defects in dogs: A retrospective study of 301 dogs
}

\author{
MAGDALENA GARNCARZ, MARTA PARZENIECKA-JAWORSKA, \\ OLGA SZALUŚ-JORDANOW*
}

\author{
Department of Pathology and Veterinary Diagnostics, Faculty of Veterinary Medicine, \\ Warsaw University of Life Sciences, Nowoursynowska 159, 02-766 Warsaw \\ *Department of Small Animal Diseases with Clinic, Faculty of Veterinary Medicine, \\ Warsaw University of Life Sciences, Nowoursynowska 159, 02-766 Warsaw
}

Garncarz M., Parzeniecka-Jaworska M., Szaluś-Jordanow O. Congenital heart defects in dogs: A retrospective study of 301 dogs

\section{Summary}

The aim of the study was to assess the frequency of congenital heart defects in a population of dogs in Poland and to determine which breeds were affected by particular defects. A retrospective study of the medical records of cardiologically examined dogs revealed 301 cases of echocardiographically confirmed congenital heart defects. Dogs with congenital heart defects made up $2.7 \%$ of the dogs that underwent a cardiologic examination. The age at diagnosis ranged from 2 weeks to 190 months. Mixed breeds (33 dogs, 11\%), Bull Terriers (31, 10\%), Boxers $(28,9 \%)$, German Shepherds $(17,6 \%)$, Yorkshire Terriers $(17,6 \%)$, and French Bulldogs $(16,5 \%)$ were the most frequently affected breeds. Subaortic stenosis $(120$ cases, 33.9\%), pulmonic stenosis $(64,18.1 \%)$, patent ductus arteriosus $(59,16.7 \%)$, mitral valve dysplasia $(56,15.8 \%)$, ventricular septal defect $(24,6.8 \%)$ and tricuspid valve dysplasia $(17,4.8 \%)$ were the most frequent congenital heart defects recognized in this study. Isolated congenital heart disease occurred in 258 dogs $(86 \%)$, while multiple heart defects were noted in 43 dogs $(14 \%)$. Most $(60 \%)$ congenital heart defects were recognized in dogs older than 1 year. Early recognition of congenital heart defects is important for better patient care. Collecting information on the frequency of congenital heart defects in particular breeds will be useful in educating breeders and thus in improving the overall health of the breed.

Keywords: congenital heart defects, dogs

The prevalence of congenital heart defects (CHD) varies depending on breed popularity in different parts of the world $(11,13,21)$. It is essential to recognize the presence of heart defects in order to decide on the best possible treatment plan for each patient, to assess prognosis, and, in the case of purebred animals, to exclude affected animals from breeding programs. The most common CHD in canine patients include aortic stenosis (AS), pulmonic stenosis (PS), patent ductus arteriosus (PDA), ventricular septal defects (VSD), mitral valve dysplasia (MD), tricuspid valve dysplasia (TD), and tetralogy of Fallot (TF) $(1,11,13,14,21)$, with the first three usually predominating $(3,18)$. The order of prevalence of these defects is related to the dog breed population in a particular geographical region. Publications in Poland have described single cases of CHD $(6,7)$, prevalence of aortic stenosis (15), tricuspid dysplasia (17), and tetralogy of Fallot (16), and a description of treatment of pulmonic stenosis (19). A large-scale study of the number and types of con- genital heart defects in Poland has not been published to date. The aim of this study was to ascertain which congenital heart defects occurred most often in the population of dogs in and around Warsaw, Poland, and which breeds were most affected by particular defects.

\section{Material and methods}

Medical records of 11,015 dogs that underwent a cardiovascular examination by one of three veterinarians at the Faculty of Veterinary Medicine, Warsaw University of Life Sciences between January 1, 2006, and May 9, 2017, were retrospectively reviewed and analyzed. An echocardiographic diagnosis of a congenital heart defect was obtained in 301 dogs. Only dogs with a full clinical chart (history, signalment, physical examination, and echocardiography) were included in the study, but for the purposes of this report further descriptive analyses were performed with respect to breed, sex, and the number of congenital defects. This study complies with national and institutional guidelines on the use of animals in clinical research according to the Polish 
legal act of January 21, 2005, concerning experiments performed on client-owned animals.

Transthoracic echocardiographic examinations were performed without the use of chemical restraint by means of the following ultrasound machines: SC300 PANDION with mechanical transducers ranging from 2.5 to $7 \mathrm{MHz}$, Mindray M7 with phase array transducers ranging from 2 to $12 \mathrm{MHz}$, and Aloka 4000 or Esaote MyLabClassCVet with 2.5-7 MHz electronic transducers. Patients were placed in right and left lateral recumbency according to accepted guidelines (20) and in some cases in a standing position. Diagnoses of congenital heart defects were based on twodimensional interrogation in combination with color and spectral Doppler interrogation. The severity of PS and AS was evaluated on the basis of spectral Doppler pressure gradients calculated from flow velocities of the respective great vessels according to published guidelines (3). Both AS and PS were classified as mild with pressure gradients of $20-49 \mathrm{mmHg}$, moderate with gradients of $50-80 \mathrm{mmHg}$ and severe with gradients above $80 \mathrm{mmHg}$.

Descriptive statistics were performed using Microsoft Excel.

\section{Results and discussion}

Dogs with CHD made up $2.7 \%$ of all the examined dogs. Of these 301 dogs with CHD, 145 (48.2\%)

Tab. 1. The number of dogs of various breeds with congenital heart defects and the types of the defects

\begin{tabular}{|c|c|c|}
\hline Breed & $\mathbf{n}$ & Congenital heart defect \\
\hline Mixed breed & 32 & $\begin{array}{l}\text { PDA (11), PS (8), SAS (3), VSD (2), } \\
\text { PS + VSD (1), SAS + PS (2), } \\
\text { SAS + PS + VSD (1), PLCVC (1), } \\
\text { MD (2), Ebstein's anomaly (1) }\end{array}$ \\
\hline Bull Terrier & 30 & $\begin{array}{l}\text { MD (11), SAS (11), SAS + PS (2), } \\
\text { SAS + PS + MD (2), SAS + MD (4) }\end{array}$ \\
\hline Boxer & 28 & $\begin{array}{l}\text { MD (1), PS (3), SAS (23), } \\
\text { SAS + PS (1) }\end{array}$ \\
\hline Golden Retriever & 27 & $\begin{array}{l}\text { SAS (15), MD (6), TD (2), } \\
M D+T D(1), S A S+M D(1), P S(1) \\
\text { PDA (1) }\end{array}$ \\
\hline German Shepherd & 17 & $\begin{array}{l}\text { PDA (9), MD (4), SAS (2), } \\
\text { ASD + PDA (1), MD + TD (1) }\end{array}$ \\
\hline French Bulldog & 16 & $\begin{array}{l}\text { PS (8), VSD (3), TD (2), SAS (1), } \\
\text { SAS + VSD + PS (1), SAS + VSD (1) }\end{array}$ \\
\hline Yorkshire Terrier & 16 & $\begin{array}{l}\text { PDA (6), PS (6), VSD (2), } \\
\text { VSD + MD (1), SAS + PS (1) }\end{array}$ \\
\hline American Stafforshire Terrier & 9 & MD (1), PS (2), SAS (6) \\
\hline Miniature Bull Terrier & 8 & SAS (4), MD (3), SAS + PS + MD (1) \\
\hline Great Dane & 7 & SAS \\
\hline Labrador Retriever & 6 & TD (3), TD + PDA (1), SAS (2) \\
\hline Maltese & 6 & $\begin{array}{l}\text { PDA (4), SAS (1), } \\
\text { SAS + MS + PDA + PLCVC (1) }\end{array}$ \\
\hline West Highland White Terrier & 6 & PS (3), SAS (2), VSD (1) \\
\hline English Bulldog & 5 & PS (4), MD (1) \\
\hline Miniature Schnauzer & 5 & PDA (3), PS + SAS (2) \\
\hline Border Collie & 4 & PDA (2), VSD (2) \\
\hline Polish Lowland Sheepdog & 4 & PDA (3), VSD (1) \\
\hline Wire Fox Terrier & 4 & $\begin{array}{l}\text { VSD, VSD + SAS + MD, VSD + PDA, } \\
\text { VSD + PDA + PS }\end{array}$ \\
\hline Weimaraner & 4 & MD (3), TD + CTD + QA (1) \\
\hline Jack Russell Terrier & 3 & PDA (2), PS (1) \\
\hline Australian Sheepdog & 2 & MD \\
\hline Belgian Sheepdog & 2 & PDA, MD \\
\hline Bullmastiff & 2 & TD (2) \\
\hline Cane corso & 2 & SAS (1), TF (1) \\
\hline Chihuahua & 2 & PDA (1), TF (1) \\
\hline
\end{tabular}

\begin{tabular}{|l|l|l|}
\hline \multicolumn{1}{|c|}{ Breed } & $\mathrm{n}$ & \multicolumn{1}{|c|}{ Congenital heart defect } \\
\hline Cocker Spaniel & 2 & PDA, PS + TD \\
\hline Dog de Bordeaux & 2 & MD, SAS \\
\hline Giant Schnauzer & 2 & SAS + PS (1), SAS + PDA (1) \\
\hline Irish Setter & 2 & PDA + MD, SAS + PS \\
\hline Manchester Terrier & 2 & PS, SAS \\
\hline $\begin{array}{l}\text { Miniature Pincher } \\
\text { Rottweiler }\end{array}$ & 2 & PS \\
\hline $\begin{array}{l}\text { Airdale Terrier } \\
\text { Bernese Mountain Dog } \\
\text { Nova Scotia Ducktolling } \\
\text { Retriever } \\
\text { Springer Spaniel }\end{array}$ & 2 & SAS, SAS + PS \\
$\begin{array}{l}\text { Bavarian Mountain Hound } \\
\text { Cavalier King Charles Spaniel } \\
\text { Dachshund } \\
\text { Griffon Bruxellois } \\
\text { Leonberger } \\
\text { Rhodesian Ridgeback } \\
\text { Rough Collie }\end{array}$ & 1 & MD \\
\hline $\begin{array}{l}\text { Ca de Bou } \\
\text { Chinese Crested Dog } \\
\text { Clumber Spaniel } \\
\text { Dalmation } \\
\text { Dogo Argentino } \\
\text { English Mastiff } \\
\text { Hovawart } \\
\text { Neapolitan Mastiff } \\
\text { Newfoundland } \\
\text { Old English Sheepdog } \\
\text { Staffordshire Bull Terrier }\end{array}$ & 1 & PDA \\
\hline $\begin{array}{l}\text { Shetland Sheepdog } \\
\text { Shih-tzu } \\
\text { Welsh Terrier }\end{array}$ & 1 & SAS \\
\hline $\begin{array}{l}\text { Flat Coated Retriever } \\
\text { Papillion } \\
\text { Siberian Husky }\end{array}$ & 1 & PS + TD \\
\hline $\begin{array}{l}\text { Pekinese } \\
\text { Central Asian Shepherd Dog } \\
\text { Pembroke Welsh Corgi }\end{array}$ & 1 & MD + TD \\
\hline $\begin{array}{l}\text { Entlebucher } \\
\text { Polish Hunting Dog }\end{array}$ & & \\
\hline \begin{tabular}{l} 
Samoyed \\
\hline
\end{tabular} & 1 & VSD \\
\hline
\end{tabular}

Explanations: ASD - atrial septal defect, CTD - cor triatriatum dextrum, MD - mitral valve dysplasia, MS - mitral valve stenosis, PDA - patent ductus arteriosus, PLCVC - persistent left cranial vena cava, PS - pulmonic stenosis, QA - quadricuspid aortic valve, SAS - subaortic stenosis, TD - tricuspid valve dysplasia, TF - tetralogy of Fallot, VSD - ventricular septal defect 
were female and 156 (51.8\%) were male. Their age at diagnosis ranged from 2 weeks to 15.8 years. CHD were diagnosed in 187 dogs aged less than 3 years $(62 \%$ of all dogs with CHD), 72 dogs aged 3-8 years (24\%), and 42 dogs aged more than 8 years (14\%). Various dog breeds were represented. Tab. 1 shows the various dog breeds represented and the congenital heart defects recognized in each breed. The most frequent dog breeds were mixed breeds (33 dogs, 11\%), Bull Terriers (31 dogs, 10\%), Boxers (28 dogs, 9\%), German Shepherds (17 dogs, 6\%), Yorkshire Terriers (17 dogs, 6\%), and French Bulldogs (16 dogs, 5\%).

The most frequent congenital heart defects recognized in this study were SAS, PS, PDA, MD, VSD, and TD. Their numbers are presented in Tab. 6 along with those of other, less frequent defects. The breed distributions of the four most frequent heart defects, SAS, PS, PDA, and MD, are shown in Tab. 2-5.

Isolated heart defects. Isolated CHD occurred in 258 dogs (86\%). Subvalvular aortic stenosis (SAS) was the most frequent single defect (93 dogs). Mild SAS occurred in 68 dogs $(73.1 \%$ of SAS $)$, moderate in $14 \operatorname{dogs}(15.1 \%$ of SAS), and severe SAS occurred in 11 dogs $(11.8 \%$ of SAS, $4.3 \%$ ). There was no available information on the severity of SAS in one dog. No valvular or supravalvular AS was seen.

PDA was diagnosed in 52 dogs, only two $(3.9 \%)$ of which had a right to left shunt, while the remaining $(96.1 \%)$ had a left to right shunt.

PS was seen in $41 \operatorname{dogs}$, the majority of which had a valvular stenosis. One dog (2.4\%) had a hypoplastic pulmonary artery (with severe stenosis), and one dog $(2.4 \%)$ had a supravalvular stenosis (mild). In 4 cases, no information on the severity of PS was available. In the remaining dogs, PS was severe in $14(34.1 \%)$ animals, moderate in $11(26.8 \%)$, and mild in $10(24.3 \%)$.

MD was diagnosed in 40 dogs, VSD in 15 dogs (all of which had
Tab. 2. Breed distribution of subaortic stenosis

\begin{tabular}{|l|r|r|}
\hline \multicolumn{1}{|c|}{ Breed } & \multicolumn{1}{c|}{$\mathrm{n}$} & \multicolumn{1}{c|}{$\%$} \\
\hline Boxer & 24 & 20.00 \\
Bull Terrier & 20 & 16.67 \\
\hline Golden Retriever & 16 & 13.33 \\
\hline Great Dane & 7 & 5.83 \\
\hline $\begin{array}{l}\text { American Staffordshire Terrier } \\
\text { Mixed }\end{array}$ & 6 & 5.00 \\
\hline $\begin{array}{l}\text { Miniature Bull Terrier } \\
\text { French Bulldog }\end{array}$ & 5 & 4.17 \\
$\begin{array}{l}\text { German Shepherd } \\
\text { Giant Schnauzer } \\
\text { Labrador Retriever } \\
\text { Maltese } \\
\text { Miniature Schnauzer } \\
\text { Rottweiler } \\
\text { West Highland White Terrier }\end{array}$ & 3 & 2.50 \\
$\begin{array}{l}\text { Cane Corso } \\
\text { Chinese Crested Dog } \\
\text { Clumber Spaniel } \\
\text { Dalmation } \\
\text { Dog de Bordeaux } \\
\text { Dogo Argentino } \\
\text { Etlebucher } \\
\text { Hovawart } \\
\text { Manchester Terrier } \\
\text { English Mastiff } \\
\text { Neapolitan Mastiff } \\
\text { Newfoundland } \\
\text { Old English Sheepdog } \\
\text { Ca De Bou } \\
\text { Rhodesian Ridgeback } \\
\text { lrish Setter } \\
\text { Staffordshire Bull Terrier } \\
\text { Wire Fox Terrier } \\
\text { Yorkshire Terrier }\end{array}$ & 2 & 1.67 \\
Total & 1 & 0.83 \\
\hline & & \\
\hline & & \\
\hline & & \\
\hline
\end{tabular}

Tab. 4. Breed distribution of patent ductus arteriosus

\begin{tabular}{|l|r|r|}
\hline \multicolumn{1}{|c|}{ Breed } & \multicolumn{1}{c|}{$\mathrm{n}$} & \multicolumn{1}{c|}{$\%$} \\
\hline Mixed breed & 11 & 18.64 \\
German Shepherd & 10 & 16.95 \\
\hline Yorkshire Terrier & 7 & 11.86 \\
\hline Maltese & 5 & 8.47 \\
\hline $\begin{array}{l}\text { Miniature Schnauzer } \\
\text { Polish Lowland Sheepdog }\end{array}$ & 3 & 5.08 \\
$\begin{array}{l}\text { Border Collie } \\
\text { lrish Setter } \\
\text { Jack Russel Terrier } \\
\text { Wire Fox Terrier }\end{array}$ & 2 & 3.39 \\
\hline $\begin{array}{l}\text { Bavarian Mountain Hound } \\
\text { Belgian Shepherd } \\
\text { Cavalier King Charles Spaniel } \\
\text { Chichuachua } \\
\text { Cocker Spaniel } \\
\text { Dachshund } \\
\text { Giant Schnauzer } \\
\text { Golden Retriever } \\
\text { Griffon Bruxellois } \\
\text { Labrador Retriever } \\
\text { Leonberger } \\
\text { Rough Collie }\end{array}$ & 1 & 1.69 \\
$\begin{array}{l}\text { Total } \\
\text { Mal }\end{array}$ & 59 & 100 \\
\hline
\end{tabular}

Tab. 3. Breed distribution of pulmonic stenosis

\begin{tabular}{|c|c|c|}
\hline Breed & n & $\%$ \\
\hline Mixed breed & 12 & 18.75 \\
\hline French Bulldog & 9 & 14.06 \\
\hline Yorkshire Terrier & 7 & 10.94 \\
\hline $\begin{array}{l}\text { Boxer } \\
\text { Bull Terrier } \\
\text { English Bulldog }\end{array}$ & 4 & 6.25 \\
\hline West Highland White Terrier & 3 & 4.69 \\
\hline $\begin{array}{l}\text { Miniature Pincher } \\
\text { American Staffordshire Terrier } \\
\text { Miniature Schnauzer }\end{array}$ & 2 & 3.13 \\
\hline $\begin{array}{l}\text { Miniature Bull Terrier } \\
\text { Cocker Spaniel } \\
\text { Entlebucher } \\
\text { Giant Schnauzer } \\
\text { Golden Retriever } \\
\text { Irish Setter } \\
\text { Jack Russel Terrier } \\
\text { Manchester Terrier } \\
\text { Neapolitan Mastiff } \\
\text { Shetland Sheepdog } \\
\text { Rottweiler } \\
\text { Samoyed } \\
\text { Shih-tzu } \\
\text { Welsh Terrier } \\
\text { Wire Fox Terrier }\end{array}$ & 1 & 1.56 \\
\hline Total & 64 & 100 \\
\hline
\end{tabular}

Tab. 5. Breed distribution of mitral valve dysplasia

\begin{tabular}{|l|r|r|}
\hline \multicolumn{1}{|c|}{ Breed } & \multicolumn{1}{c|}{$\mathrm{n}$} & \multicolumn{1}{c|}{$\%$} \\
\hline Bull Terrier & 17 & 30.36 \\
\hline Golden Retriever & 8 & 14.29 \\
\hline German Shepherd & 5 & 8.93 \\
Miniature Bull Terrier & 4 & 7.14 \\
\hline Weimaraner & 3 & 5.36 \\
Mixed breed & 2 & 3.57 \\
Australian Shepherd & & \\
$\begin{array}{l}\text { Airdale Terrier } \\
\text { American Staffordshire Terrier } \\
\text { Bernese Mountain Dog } \\
\text { Boxer } \\
\text { English Bulldog } \\
\text { Dog de Bordeaux } \\
\text { Polish Hunting Dog } \\
\text { Nova Scotia Duck Tolling } \\
\text { Retriever } \\
\text { Belgian Shepherd } \\
\text { Central Asian Shepherd Dog } \\
\text { lrish Setter } \\
\text { Springer Spaniel } \\
\text { Welsh Corgi Pembroke } \\
\text { Wire Fox Terrier } \\
\text { Yorkshire Terrier }\end{array}$ & 1.79 \\
$\begin{array}{l}\text { Total } \\
\text { Tot }\end{array}$ & & \\
\hline
\end{tabular}


Tab. 6. Isolated and associated congenital heart defect distribution

\begin{tabular}{|c|c|c|c|c|c|c|}
\hline Defect & n (\%) & Isolated & Associated & Male & Female & $\begin{array}{c}\text { Age at first diagnosis } \\
\text { (months): median (range) }\end{array}$ \\
\hline SAS & $120(33.9 \%)$ & 93 (77.5\%) & 27 (22.5\%) & 57 (47.5\%) & $63(52.5 \%)$ & $26.5(2-177)$ \\
\hline PS & $64(18.1 \%)$ & $41(64.0 \%)$ & $23(36.0 \%)$ & $47(73 \%)$ & $17(27 \%)$ & $36(2-169)$ \\
\hline PDA & $59(16.7 \%)$ & $52(88.1 \%)$ & $7(11.9 \%)$ & $20(34 \%)$ & $39(66 \%)$ & $15(1-180)$ \\
\hline MD & $56(15.8 \%)$ & 40 (71.4\%) & $16(28.6 \%)$ & $30(54 \%)$ & $26(46 \%)$ & $22.5(0.5-144)$ \\
\hline VSD & $24(6.8 \%)$ & $15(62.5 \%)$ & $9(37.5 \%)$ & $14(58 \%)$ & $10(42 \%)$ & $9(1-130)$ \\
\hline TD & 17 (4.8\%) & $9(53.0 \%)$ & $8(47.0 \%)$ & $11(65 \%)$ & $6(35 \%)$ & $17(0.5-140)$ \\
\hline PLCVC & $6(1.7 \%)$ & $4(66.7 \%)$ & $2(33.3 \%)$ & $3(50 \%)$ & $3(50 \%)$ & $120.5(2-190)$ \\
\hline TF & $3(0.9 \%)$ & $3(100 \%)$ & $0(0 \%)$ & $1(33 \%)$ & $2(67 \%)$ & $10(3-10)$ \\
\hline EbA & $1(0.3 \%)$ & $1(100 \%)$ & $0(0 \%)$ & $1(100 \%)$ & $0(0 \%)$ & 6 \\
\hline ASD & $1(0.3 \%)$ & $0(0 \%)$ & $1(100 \%)$ & $0(0 \%)$ & $1(100 \%)$ & 24 \\
\hline CorT & $1(0.3 \%)$ & $0(0 \%)$ & $1(100 \%)$ & $1(100 \%)$ & $0(0 \%)$ & 17 \\
\hline MS & $1(0.3 \%)$ & $0(0 \%)$ & $1(100 \%)$ & $0(0 \%)$ & $1(100 \%)$ & 2 \\
\hline QA & $1(0.3 \%)$ & $0(0 \%)$ & $1(100 \%)$ & $1(100 \%)$ & $0(0 \%)$ & 17 \\
\hline Total & $354(100 \%)$ & & & & & \\
\hline
\end{tabular}

Explanations: SAS - subaortic stenosis, PS - pulmonic stenosis, PDA - patent ductus arteriosus, VSD - ventricular septal defect, TD - tricuspid valve dysplasia, PLCVC - persistent left cranial vena cava, TF - tetralogy of Fallot, EbA - Ebstein's anomaly, ASD - atrial septal defect, CorT - cor triatiratum dexter, MS - mitral stenosis, QA - quadricuspid aortic valve

a L-R shunt), TD in 9 dogs, PLCVC in 4 dogs, and TF in 3 dogs. EbA was seen in only one dog.

Multiple heart defects. Multiple CHD occurred in 43 dogs (14\%). One dog had four separate abnormalities, 8 dogs had a combination of 3 defects, while 33 dogs had two separate defects. The most frequent combination of congenital heart defects was SAS and PS. MD also occurred often in association with SAS and PS (3 dogs), SAS alone (5 dogs), and TD (4 dogs).

Tab. 6 shows the percentage distribution of particular single and multiple congenital heart defects. Tab. 7 shows the exact combinations of multiple heart defects and the breeds in which they were recognized.

The most frequent congenital heart defects in this study were SAS, PS, and PDA. These findings are consistent with many previous reports $(1,2,13,18$, $21)$. Most studies recognized VSD as the $3^{\text {rd }}$ or $4^{\text {th }}$ most frequent defect $(1,13,21)$, but in the present study MD took the $4^{\text {th }}$ place, possibly because of the overrepresentation of Bull Terriers (the most frequent breed with MD). Bull Terriers have become a popular breed recently, and many owners/breeders choose to perform voluntary heart checks to rule out heart disease. This might account for the increased number of examinations and therefore recognized defects in otherwise asymptomatic dogs.

The occurrence of CHD was nearly equal in males and females, but females were more often affected with PDA (66\% females) and TF (67\%), while males more often suffered from PS (73\%) and TD $(65 \%)$. This is similar to what another study has shown (13), with the exception of TD, which in that study was evenly distributed. There was an earlier study, which showed that males were more often affected with TD (21), as in the present study. The differences may be attributed to breed distribution in different countries.

Most studies do not look at the age of dogs at diagnosis. Oliveira et al (13) showed that the average age at diagnosis was over 2 years and justifiably underline the importance of early diagnosis. In the present study, only $91(30 \%)$ dogs were 1 year or younger, which is the best time to identify CHD. Most dogs were diagnosed as adults. This most probably results from the fact that mild disease is asymptomatic and the owners are not inclined to bring their pets in for heart testing when the dogs appear healthy. In addition, congenital heart defects sometimes do not present with heart murmurs, and therefore further heart testing does not seem warranted.

The present study showed a similar predisposition to SAS as previous reports in Boxers, Golden Retrievers, German Shepherds, mixed breeds $(2,4,12,13,15)$, and Bull Terriers (15). This study showed two more breeds, Great Danes and Miniature Bull Terriers, that have not been previously reported. Miniature Bull Terriers may be overrepresented due to their increased popularity and a high number of voluntary heart examinations in Poland. There was no apparent difference in the number of male or female dogs with SAS, which is similar to one study (21), but not another (13), which showed a male predisposition. These discrepancies may simply be due to the popularity of different breeds in each country, such as Sweden (21) and Italy (13), and Poland in this study.

A high number of mixed breeds, French Bulldogs, and Yorkshire Terriers were diagnosed with PS. These breeds have previously been described as predisposed to this defect $(2,9,13,21)$. Other breeds that have also 
Tab. 7. Various combinations of multiple congenital heart defects in 43 dogs

\begin{tabular}{|c|c|c|}
\hline Combination of defects & $\begin{array}{l}\text { Number } \\
\text { of dogs }\end{array}$ & Dog breeds \\
\hline \multicolumn{3}{|c|}{4 defects } \\
\hline SAS + MS +PDA + PLCVC & 1 & Maltese (F) \\
\hline \multicolumn{3}{|c|}{3 defects } \\
\hline SAS + PS + MD & 3 & Bullterrier (2 F, $1 \mathrm{M})$ \\
\hline$S A S+V S D+P S$ & 2 & $\begin{array}{l}\text { Mixed breed }(F) \\
\text { French Bulldog (F) }\end{array}$ \\
\hline$S A S+V S D+M D$ & 1 & Smooth Fox Terrier (M) \\
\hline $\mathrm{TD}+\mathrm{CTD}+\mathrm{QA}$ & 1 & Weimaraner (M) \\
\hline$P D A+P S+V S D$ & 1 & Smooth Fox Terrier (M) \\
\hline \multicolumn{3}{|c|}{2 defects } \\
\hline PS + SAS & 13 & $\begin{array}{l}\text { Miniature Schnauzer (2, both M) } \\
\text { Mixed breed (2, both F) } \\
\text { Boxer (M) } \\
\text { Giant Schnauzer (M) } \\
\text { Irish Setter (M) } \\
\text { Rottweiler (M) } \\
\text { Entlebucher (M) } \\
\text { Bullterrier (1 M, 1 F) } \\
\text { Yorkshire Terrier (F) } \\
\text { Neapolitan Mastiff (M) }\end{array}$ \\
\hline SAS + MD & 5 & $\begin{array}{l}\text { Bullterier (3 F, } 1 \mathrm{M}) \\
\text { Golden Retriever (M) }\end{array}$ \\
\hline MD + TD & 4 & $\begin{array}{l}\text { Central Asian Shepherd Dog (F) } \\
\text { German Shepherd (M) } \\
\text { Pembroke Welsh Corgi (F) } \\
\text { Golden Retriever (F) }\end{array}$ \\
\hline PS + TD & 2 & $\begin{array}{l}\text { Samoyed (M) } \\
\text { English Cocker Spaniel (M) }\end{array}$ \\
\hline VSD + MD & 2 & $\begin{array}{l}\text { Yorkshire Terrier (M) } \\
\text { Polish Hunting Dog (M) }\end{array}$ \\
\hline PDA + MD & 1 & Irish setter (M) \\
\hline PDA + TD & 1 & Labrador Retriever (F) \\
\hline PDA + VSD & 1 & Smooth Fox Terrier (M) \\
\hline PDA + ASD & 1 & German Shepherd (F) \\
\hline PDA + SAS & 1 & Giant Schnauzer (M) \\
\hline PS + VSD & 1 & Mixed breed (M) \\
\hline PS + PLCVC & 1 & American Staffordshire Terrier \\
\hline SAS + VSD & 1 & French Bulldog (F) \\
\hline Total number of dogs & 43 & \\
\hline
\end{tabular}

Explanations: ASD - atrial septal defect, CTD - cor triatriatum dextrum, MD - mitral valve dysplasia, $\mathrm{MS}$ - mitral valve stenosis, PDA - patent ductus arteriosus, PLCVC - persistent left cranial vena cava, PS - pulmonic stenosis, QA - quadricuspid aortic valve, SAS - subaortic stenosis, TD - tricuspid valve dysplasia, VSD - ventricular septal defect

been described as predisposed did not show up in this study in comparable numbers, including Boxers, which are often seen as one of the breeds most predisposed to PS $(2,11,13)$. Although not one of the most common breeds, Bull Terriers were relatively highly represented in this study, but only one study mentions a minimally increased frequency of PS in this breed (5). The increased incidence in this study may once again result from screening for heart disease before inclusion into a breeding program.

PDA occurs with different frequencies, depending on the geographical location. It has been named the $1^{\text {st }}(2), 2^{\text {nd }}(10), 3^{\text {rd }}(13)$, and $4^{\text {th }}(1,21)$ most common CHD. This study showed PDA to be the third most frequent defect, as in the California population (10). It occurred most often in mixed breed dogs, German Shepherds, Yorkshire Terriers, and Maltese, all breeds classified as predisposed in previous reports $(2,10,13$, 21). The Miniature Schnauzer is also described as being at increased risk for PDA (2), but in this study only $3(5 \%)$ dogs were affected. Similarly, 3 (5\%) Polish Lowland Sheepdogs were diagnosed with PDA, but this breed has not previously been reported to have a predisposition.

The frequency of MD cases was much higher $(15.8 \%)$ in this study than the previously reported $1.9 \%(13), 8.0 \%(21)$, and $1.7 \%$ (2). This may partly be due to the increased number of Bull Terriers presented to the examiners for heart examinations for breeding purposes. At present, there is only anecdotal information on the predisposition of Bull Terriers to MD (2). The present study did show that 11 (35.5\%) of the 31 Bull Terriers with CHD had MD. Of all the dogs with MD, Bull Terriers were the most frequent (17 dogs, i.e. $30 \%$ of dogs with MD), followed by Golden Retrievers (8 dogs, 14\%), German Shepherds (5 dogs, 9\%), Miniature Bull Terriers (4 dogs, 7\%), and Weimaraners (3 dogs, 5\%). Of these breeds, only the German Shepherds and Golden Retrievers have previously been described as having $\operatorname{MD}(2,21)$.

Although VSD was the $5^{\text {th }}$ most common defect in this study, the percentage of affected dogs was similar to that reported in previous studies, with $7.5 \%$ in one study (13) and 9.8\% in another (1). Two other studies have shown a greater frequency of this defect, with $14.4 \%$ in one study (1) and $12.3 \%$ in another (21), but in both those studies VSD was the $3^{\text {rd }}$ most frequent congenital heart defect. VSD was most often recognized in French Bulldogs, mixed breeds, Wire Fox Terriers, Yorkshire Terriers, and Border Collies, but only the first two of these breeds have previously been described as predisposed to $\operatorname{VSD}(2,13)$. Flat-coated retrievers have previously been described (21), but in the present study only one dog $(4 \%)$ of this breed was diagnosed with VSD.

TD was most frequently seen in Labrador Retrievers and Golden Retrievers, which is consistent with a previous study on TD in Poland (17) and other reports (2, 13). The other breeds reported in this study have not previously been described (i.e. French Bulldog and Bullmastiff).

PLCVC has not been previously reported in an analysis of a larger population of dogs. It is mostly considered an incidental finding and therefore receives little attention. In this study, it occurred concomitantly 
with other defects in $2(33.3 \%)$ cases, but not in the same combination (1 PS, 1 SAS + MS + PDA), so this was probably not a significant finding.

Multiple defects were clearly less frequent compared to isolated CHD. The results of the present study, in which multiple defects were twice as frequent as in previous studies $(1,21)$, are similar to those reported by Oliveira et at. (13). The combination of SAS and PS was the most frequent, accounting for $30 \%$ of all multiple defects, which confirms previous studies showing the same tendency $(4,8,13,21)$. Kander et al. (8) showed a somewhat different breed distribution, with Boxers being affected more often than in this study, in which a variety of breeds were represented (Tab. 7).

This study shows the frequency of different CHD in Poland, the breeds most affected, and tendencies relatively similar to those in other such studies in different geographical areas. The most common defects are SAS and PS, as in other reports. The order of the remaining defects differs somewhat from those reported in previous studies, with PDA being the $3^{\text {rd }}$, MD the $4^{\text {th }}$, VSD the $5^{\text {th }}$, and TD the $6^{\text {th }}$ most common defect in this study. Several breeds that have not previously been mentioned as predisposed to CHD are reported in this study, including Great Danes and Miniature Bull Terriers with SAS, Bull Terriers with PS, Polish Lowland Sheepdogs with PDA, Bull Terriers, Miniature Bull Terriers, and Weimaraners with MD, Wire Fox Terriers, Yorkshire Terriers, and Border Collies with VSD, and French Bulldogs and Bullmastiffs with TD. To the authors' best knowledge, this is the first report to include the frequency of PLCVC. The relatively high incidence of multiple CHD underlines the importance of a complete echocardiographic examination, even when one defect has already been recognized. The veterinary profession should strive to recognize CHD early in the dog's life, which would give breeders information about the presence of a possible genetically based CHD. This, along with the education of breeders on breed susceptibility to CHD, would allow them to make medically sound decisions regarding their breeding stock, as well as allow for early interventional treatment when possible, and provide information about the disease prognosis.

\section{List of abbreviations}

$\begin{array}{ll}\text { AS } & \text { - aortic stenosis } \\ \text { ASD } & \text { - atrial septal defect, } \\ \text { CHD } & \text { - congenital heart defect } \\ \text { CTD } & \text { - cor triatriatum dextrum, } \\ \text { EbA } & \text { - Ebstein's anomaly, } \\ \text { MD } & \text { - mitral valve dysplasia, } \\ \text { MS } & \text { - mitral valve stenosis, } \\ \text { PDA } & \text { - patent ductus arteriosus, } \\ \text { PLCVC } & \text { - persistent left cranial vena cava, } \\ \text { PS } & - \text { pulmonic stenosis, } \\ \text { QA } & \text { - quadricuspid aortic valve, } \\ \text { SAS } & \text { - subaortic stenosis, } \\ \text { TD } & \text { - tricuspid valve dysplasia, } \\ \text { TF } & \text { - tetralogy of Fallot, } \\ \text { VSD } & - \text { ventricular septal defect. }\end{array}$

\section{References}

1. Baumgartner C., Glaus T. M.: Congential cardiac diseases in dogs: a retrospective analysis. Schweiz. Arch. Tierheilkd. 2003, 145, 527-536.

2. Buchanan J. W.: Prevalence of cardiovascular disorders, [in:] Fox P. R., Sisson D. D., Moise N. S., (ed.): Textbook of Canine and Feline Cardiology. $2^{\text {nd }}$ ed, WB Saunders Company, Philadelphia, PA 1999, p. 459-463.

3. Bussadori C., Amberger C., Le Bobinnec G., Lombard C. W.: Guidelines for the echocardiographic studies of suspected subaortic and pulmonic stenosis. J. Vet. Cariol. 2000, 2, 15-22.

4.Bussadori C., Quintavalla C., Capelli A.: Prevalence of Congenital Heart Disease in Boxers in Italy. J. Vet. Cardiol. 2001, 3, 7-11.

5.Francis A. J., Johnson M. J. S., Gulshaw G. C., Corcoran B. M., Martin M. W. S., French A. T.: Outcome in 55 dogs with pulmonic stenosis that did not undergo balloon valvuloplasty or surgery. J. Sm. An. Prac. 2011, 52, 282-288

6. Garncarz M., Czubek A.: Clinical case of tetralogy of Fallot: A congenita heart defect in a dog. Med. Weter. 2004, 60, 711-714.

7. Janiszewski A., Pasławska U., Cepiel A., Noszczyk-Nowak A.: Late Amplatzer device displacement after percutaneous PDA embolization: Case description. Med. Weter. 2017, 73, 183-185.

8. Kander M., Pasławska U., Staszczyk M., Cepiel A., Pasławski R., Mazur G., Noszczyk-Nowak A.: Retrospective analysis of occurrence of congenital aortic and pulmonary artery stenosis in dogs. Pol. J. Vet. Sci. 2015, 18, 841-845

9. Kienle R. D.: Congenital Pulmonic Stenosis, [in:] Kittleson M. D., Kienle R. D. (ed.): Small Animal Cardiovascular Medicine. Mosby, Inc., St. Louis, MO 1998, p. 248-259.

10. Kittleson M. D.: Patent Ductus Arteriosus, [in:] Kittleson M. D., Kienle R. D. (ed.): Small Animal Cardiovascular Medicine. Mosby, Inc., St. Louis, MO 1998, p. 219-230.

11. Manczur F., Hetyey C., Reiczigel J.: Occurrence of canine cardiological diseases in Hungary (1997-2000). Mag. Allat. Lapja 2003, 125, 669-682.

12. O'Grady M. R., Holmber D. L., Miller C. W., Cockshutt J.: Canine congenital aortic stenosis: A review of the literature and commentary. Can. Vet. J. 1989, 30, 811-815.

13. Oliveira P., Domenech O., Silva J., Vannini S., Bussadori R., Bassadori C. Retrospective Review of Congenital Heart Disease in 976 Dogs. J. Vet. Intern. Med. 2011, 25, 477-483.

14. Oyama M. A., Sisson D. D.: Evaluation of canine congenital heart disease using an echocardiographic algorithm. J. Am. Anim. Hosp. Assoc. 2001, 37, 519-535

15. Pasławska U., Cepiel A., Noszczyk-Nowak A., Staszczyk M., Janiszewski A.: Epidemiological prevalence of aortic stenosis in dogs in Poland. Med. Weter. 2014, 70, 550-552.

16. Pasławska U., Noszczyk-Nowak A., Cepiel A., Staszczyk M., Janiszewski A.: A retrospective study of tetralogy of Fallot in dogs. Turk. J. Vet. An. Sci. 2013, 37, 57-60.

17. Pasławska U., Noszczyk-Nowak A., Janiszewski A., Nicpoń J.: Tricuspid Dysplasia in Dogs. Bull. Vet. Inst. Pulawy 2013, 57, 123-126.

18. Schneider M., Schneider I., Neu H.: Feasibility of sonography in the diagnosis of congenital heart diseases in dogs. Tierarytl. Prax. Ausg. K. Kleintiere Heimtiere 1998, 26, 170-179.

19.Skrzypczak P., Pasławska U., Biały D., Atamaniuk W.: Balonoplastyka zastawkowego zwężenia tętnicy płucnej u psów. Med. Weter. 2007, 63, 1607 -1610 .

20. Thomas W. P., Gaber C. E., Jacobs G. J., Kaplan P. M., Lombard C. W., Moise N. S., Moses B. L.: Recommendations for standards in transthoracic two dimensional echocardiography in the dog and cat. Committee of the Specialty of Cardiology, American College of Veterinary Internal Medicine. J. Vet. Intern. Med. 1993, 7, 247-252.

21. Tidholm A.: Retrospective study of congenital heart defects in 151 dogs. J. Small Anim. Pract. 1997, 38, 94-98.

Corresponding author: Magdalena Garncarz, DVM, PhD, Nowoursynowska 159, 02-766 Warsaw, Poland; e-mail: magdalena_garncarz@sggw.pl, magdagarncarz@yahoo.com 